palliative care is part of routine medical and nursing education, and every nurse and doctor would be able to practise it up to a point. But modern pain management, principles of communication and end of life care have become a part of the medical curriculum of the Medical Council of India only from 2019. Hence, it is vitally important to provide training on these aspects to healthcare workers treating Covid-19.

In addition to empowering the medical and nursing staff to treat symptoms and making medicines available, it is important to create a system for treating psychosocial suffering. The involvement of counsellors or medical social workers in Covid-19 management can be of substantial help. Even if the family is unable to personally visit the patient, can virtual meetings not be made a routine practice? Being able to see the family on a mobile phone and being able to say "I love you" does matter more than medical technologists can imagine. When faith-based rituals are challenged, can technology not facilitate them, for example, a last communion?

\section{Conclusion}

Many unique features of Covid-19 challenge the fundamental ethical principles of autonomy, beneficence, non-maleficence and justice. It is important to focus on the primary duty of the healthcare provider to mitigate suffering. Many elements of suffering presented by Covid-19 disease need to be overcome with a strategy focusing on health-related suffering. Attention to symptom control can be ensured by online education of treating doctors and by making essential medicines available including controlled medicines. Much psychosocial suffering can be lessened by equipping healthcare providers with the required training, by recruitment and empowerment of medical social workers or counsellors, and by the use of technology including mobile phones. For the dying and their families, a final farewell at least with a telephone conversation would ease the ache of the loss somewhat. Amidst all the horror of the abrupt loss, such a conversation could well be one that brings a little peace to the dying and a precious memory for the bereaved family to cherish.

References

1. Draulans D.'Finally, a virus got me.' Scientist who fought Ebola and HIV reflects on facing death from COVID-19. Science. 2020 May 8[cited 2020 May 30]. Available from: https://www.sciencemag.org/news/2020/05/ finally-virus-got-me-scientist-who-fought-ebola-and-hiv-reflectsfacing-death-covid-19\#

2. Indian Council of Medical Research. Definition of terms used in limitation of treatment and providing palliative care at end of life. 2018 Mar 12 [cited 2020 Jun 3]. Available from:https://main.icmr.nic.in/ sites/default/files/Books/Definition_of_terms_used_in_limitation_of_ treatment_and_providing_palliative_care_at_end_of_life.pdf

3. Edassery D. Pain - when it affects the person. J Pain Palliat Care Pharmacother. 2011;25(4): 372-3.

4. Richardson S, Hirsch JS, Narasimhan M, Crawford JM, McGinn T, Davidson KW, et al. Presenting characteristics, comorbidities, and outcomes among 5700 patients hospitalized with COVID-19 in the New York City Area. JAMA. 2020 Apr 22; 323(20): 2052-9.

5. Seventy-Third World Health Assembly. Agenda item 3. COVID 19 response. World Health Organization. 2020 May 18 [cited 2020 Jun 3]. Available from: https://apps.who.int/gb/ebwha/pdf_files/WHA73/ A73_CONF1Rev1-en.pdf

\title{
AYUSH, modern medicine and the Covid-19 pandemic
}

\section{SARIKA CHATURVEDI, NANDINI KUMAR, GIRISH TILLU, SHARAD DESHPANDE, BHUSHAN PATWARDHAN}

\section{Abstract}

The COVID-19 pandemic has posed several challenges to the Indian healthcare system. Here, we examine the situation in India

\footnotetext{
Authors: Sarika Chaturvedi (saikabharat2005@gmail.com), Dr D Y Patil Vidyapeeth (DPU), Pimpri, Pune 18, INDIA: Nandini Kumar (nandkku@yahoo. com),Former Deputy Director General Sr. Grade, Indian Council of Medical Research, and Vice President, Forum for Ethics Review Committees in India, Padmalaya Apartments, Balakrishnan Road, Thiruvanmiyur, Chennai 600 041 INDIA; Girish Tillu (gtillu@gmail.com), AYUSH Centre of Excellence, Centre for Complementary and Integrative Health, Interdisciplinary School of Health Sciences, Savitribai Phule Pune University, Pune 411 007, INDIA; Sharad Deshpande (sharad.unipune@gmail.com), Former Professor and Head, Department of Philosophy, University of Pune, and I.C.P.R. Visiting Professor, (2015-2016), IIAS, Shimla, India; Bhushan Patwardhan (corresponding author - bpatwardhan@gmail.com), AYUSH Centre of Excellence, Centre for Complementary and Integrative Health, Interdisciplinary School of Health Sciences, Savitribai Phule Pune University, Pune 411 007, INDIA

To cite: Chaturvedi S, Kumar N, Tillu G, Deshpande S, Patwardhan B. AYUSH modern medicine and the Covid-19 pandemic. Indian J Med Ethics 2020 JulSep; 5(3) NS: 191-5. DOI:10.20529/JJME.2020.058

Published online on May 13, 2020

Peer Reviewer: An anonymous peer reviewer

(c) Indian Journal of Medical Ethics 2020
}

considering the moral and ethical imperatives of decision making for public health. Currently, in the absence of proven therapies, empirical evidence is being used for treatment of Covid-19 disease. We find a dual standard of practice. Currently, only modern medicine (MM) therapies are used on an empirical basis, however, the same principle is not considered for the use of AYUSH systems. Appropriate use of evidence is required. In the ethics context and in the interest of the larger public good, we suggest the inclusion of simple and safe measures from AYUSH systems in the integrative protocols for prophylaxis and treatment of Covid-19.

Keywords: AYUSH systems, Covid-19, pandemic, prophylaxis, evidence, empirical evidence, priority setting, public health decision making, global health emergencies,complementary medicine, integrative healthcare

\section{Background}

The COVID-19 pandemic has compelled governments and the medical fraternity to make hard choices for its prevention, control and management. The urgent need for decision making regarding treatment, confronted with limited available information, makes it difficult to balance the common good 
with individual freedoms; and the need to contain its spread against economic losses. These choices ought to be guided by both scientific knowledge and ethical considerations. In the wake of the Severe Acute Respiratory Syndrome (SARS), Middle East Respiratory Syndrome (MERS), Ebola and other epidemics, several agencies such as the World Health Organisation (WHO) (1), the Nuffield Council of Bioethics (2) , the European Commission (3), Human Health Services, USA (4) and the United States Food and Drug Administration (5) have developed guidance for response in global health emergencies. A few independent frameworks to foster ethical decision making in times of crisis have also been developed (6). The WHO guidance on ethical considerations in developing a public health response to pandemic influenza recommends that policy makers should develop a process for setting priorities and promoting equitable access (7). It is also expected that "duty bearers" should ensure that their decisions are transparent, fair, help in reducing suffering and treat all people as morally equal. Notably, the WHO guidance mentions that the public is entitled to timely and accurate information on the availability of drugs for prophylaxis, treatment, and other measures. Here, we examine the Covid-19 situation in India in the light of this international guidance.

Covid-19 has posed several challenges to the Indian healthcare system. The number of cases and deaths is rising continuously, currently involving more than half of the districts in the country (8). The world's biggest lockdown was ordered in India, first for 21 days, and then extended further to a total of 55 days. The necessity for a lockdown to ensure compliance with social / physical distancing is resulting in huge economic losses and socio behavioural consequences which may unravel in the near future. The resource-poor healthcare system in India, with persistent shortages of personnel and equipment, may not be able to sustain an emergency response on the scale required for management of the Covid-19 pandemic. Hence, effective prevention, early control and less resource intensive management are most essential for the Indian situation.

\section{Current status of Covid-19 treatment in India}

The current therapy for Covid-19 involves only symptomatic treatment, supportive care and prevention of complications; however, no specific drug or targeted intervention is available yet. The repurposed experimental drugs being tested include hydroxychloroquine (HCQ), remdesivir, lopinavir/ritonavir, in combination with or without Interferon $\beta$ 1a (WHO SOLIDARITY trial) (9), experimental vaccine, convalescent plasma, manipulated cells and sometimes high dose steroids. These drugs, except HCQ and steroids, are very costly or involve complicated procedures of production, and all of these could cause serious adverse events. Therefore, the best and most cost-effective strategy would be primary prevention by reducing exposure to the pathogen, controlling its spread, arresting progress and enhancing individual immunity by using safer and natural immnunomodulating agents.

HCQ for Covid-19 prophylaxis is under investigation globally. The Indian Council of Medical Research (ICMR) has recommended its use in high-risk individuals including asymptomatic frontline health workers and asymptomatic household contacts of laboratory confirmed individuals (10). In India, the prevention and treatment of Covid-19 has largely been restricted to modern medicine (MM) / biomedicine (BM); whereas, China has successfully integrated Traditional Chinese Medicine (TCM) into mainstream healthcare (11). Historically, India has followed a pluralistic system where the choice to select suitable treatment remains with patients. The Indian government has recognised traditional systems, namely, Ayurveda, Yoga and Naturopathy, Unani, Siddha, Sowa Rigpa and Homeopathy (AYUSH), which are regulated by an independent Ministry of AYUSH. Each of these systems has its own educational policy, standards for professional qualifications, registry of practitioners and research council.

Indian policy makers, since independence, have emphasised the integrative approach involving traditional and modern medicine in preventive and curative services; while the 2017 National Health Policy mentions mainstreaming AYUSH (1214). Globally, integrative approaches for health have become increasingly acceptable (15). However, in the context of the Covid-19 epidemic in India, patients are offered only MM treatment (16). A few exceptions are emerging in some states such as Kerala (17) and Gujarat (18) that have boldly adopted an integrative approach, with media reports of success in the prevention and control of COVID-19. The neglect of the integrative approach is not merely pronounced, but is also contradictory to the nation's policy and to its pluralistic cultural foundation. AYUSH treatments have been kept out of the options available to Covid-19 patients. Besides, AYUSH human resources in the public services have been deprived of opportunities to include these interventions and are almost compelled to follow only MM-based guidelines. As yet, there is no proven standard of care established for prophylaxis or treatment in MM for the new disease, Covid-19. Allopathic drugs are currently used solely on an empirical basis. However, the same principle is not considered for the application of AYUSH systems. This dual standard of practice raises ethical considerations in advancing one particular therapy over the other, and therefore deserves to be examined and revised.

\section{Ethics of neglecting available therapies}

Ayurveda recommends local and systemic prophylaxis measures for respiratory diseases that may be beneficial in COVID-19 prevention. These include the use of medicated water, mouth rinse and gargle, steam inhalation, nasal oil application and use of Rasayana as immune strengthening therapy. Reasonably good empirical evidence is available in support of these measures. There are also some age-old traditional practices in popular use. Support for the inclusion of these as public health measures for Covid-19 prophylaxis has garnered international attention (19). Respecting individual autonomy is an ethical principle giving a person the freedom to voluntarily choose a treatment. The person's preference should be respected by providing all the relevant details 
about available evidence from the prevalent systems of medicine. Not informing patients of established and available alternatives is unethical. The use of non-pharmacological approaches such as psycho-neuro-immunity for Covid-19 prophylaxis that include diet, sleep and immunity boosting is gaining attention (20). Similar approaches are well reportedin Ayurveda, Yoga, Unani, Siddha and Sowa Rigpa systems. However, despite the supportive evidence of longstanding practice in India, these measures are not integrated with the prophylaxis and management of Covid-19 within the health system. The Ministry of AYUSH has released its independent advisory to people for self -care measures, which has received an enthusiastic response (21).

The Ayurvedic Rasayanas are known for their immunomodulation and rejuvenation properties, which are important in Covid-19 management. Several in vitro, animal and clinical studies have demonstrated the immunomodulatory effects of the Rasayana drugs such as Ashwagandha (Withania somnifera), Guduchi (Tinospora cordifoloia), Amalaki (Emblica officinale) among many others $(22,23)$. We believe there is convincing evidence of the immunomodulating property of Ayurvedic Rasayana, especially of Ashwagandha and Guduchi, and therefore, they are strong candidates for use in Covid-19 prophylaxis and management. Some classical formulations such as Sudarshan ghana vati and Sanshamani vati are used as safer symptomatic measures for conditions such as coryza and fever. Despite the available empirical evidence, these interventions have not been considered for clinical use during the pandemic. From a moral standpoint, the dangers of not attending to evidence are as significant as ethical issues in its application.

The National Taskforce on Covid-19 constituted by the Indian Council of Medical Research (ICMR) has recommended a protocol for the use of $\mathrm{HCQ}$ as prophylaxis for the protection of high-risk individuals against Covid-19. The Drugs Controller General of India has approved this protocol for restricted use under emergency conditions (24). It is important to note that the decision to use HCQ on Covid-19 patients lacks any proof of concept and pharmacokinetic study in the same context. This means there is insufficient evidence to recommend HCQ for Covid-19 prophylaxis. Interestingly, in a well-controlled study in rheumatoid arthritis, the clinical efficacy of HCQ was found to be equivalent to an Ashwagandha formulation (25) Another study has reported that chloroquine was no better than an analgesic in the treatment of chikungunya (26). Several recent articles in scientific journals have raised questions regarding the use of HCQ as prophylaxis in Covid-19 (27) Moreover, the ICMR guidelines are silent on what is to be done by these high-risk individuals after the prescribed seven-week treatment(10). It would be scientifically incorrect to assume that they will be protected beyond this period. It would also be ethically incorrect to leave them to their fate after this period, in the light of the reported possibility of re-infection (28).

There has been longstanding neglect of the Indian systems of medicine (29) until recently. . The AYUSH systems have received increased government support after the establishment of the Ministry of AYUSH. However, this has not translated into drawing on AYUSH resources in tackling the current pandemic, and this may result in huge societal costs. While there is a moral obligation to use all available resources for the greater good, what we are currently witnessing appears to be a refusal to accept empirical evidence in support of the immunomodulatory potential of Ayurvedic Rasayana and other AYUSH measures. This is neither in the people's interest nor that of science, besides being unethical.

Linking ethical analysis with empirical evidence is important for policy decisions. Norman Daniels, in his framework for priority setting argues that the decision making process of policy makers should be fair and transparent, as they are accountable for the reasonableness of their decisions (30). The procedural conditions to guarantee fair decisions recommended in public health ethics include transparency, reasonable explanation and openness to revision, in addition to adherence to regulation. On this premise, the decision not to include evidence from the Indian AYUSH systems in the search for solutions and management of Covid-19 seems unreasonable and unfair.

In proposing a framework for decision making in public health, Tannahill proposes that while there is a "moral imperative" for evidence-based medicine, an "ethical imperative" for public health with implications for accountability is to use available evidence "appropriately to inform judgements" (31). However, it appears that with the dominance of MM/BM, the search for evidence of effectiveness is skewed towards interventions relating only to $\mathrm{MM} / \mathrm{BM}$. Appropriate use of the available evidence calls for breaking down the silos of medical systems and making decisions in the spirit of public health gains. Every medical system should strictly adhere to the principles of quality, safety, science and ethics.

The Ministry of AYUSH is making serious efforts to promote a culture of interdisciplinary collaboration without losing the basic principles of the respective systems. It must be noted that the Ministry of Health and Family Welfare is also encouraging integrative approaches. The establishment of an Interdisciplinary AYUSH Research and Development Taskforce on Covid-19 is a positive step in this direction. Appropriate exploration of AYUSH systems of medicine for solutions to Covid-19 is urgently needed. At this juncture, any delay is bound to cost society and science dearly. The opportunity to undo unfair decisions and to open the door to evidence from the AYUSH systems is not yet lost. Actively promoting the Ayurveda, Siddha, Unani, Sowa Rigpa, Homeopathy medicines, and Yoga and Naturopathy interventions showing empirical evidence might benefit many more, with a minimal potential for harm. More research is certainly needed to confirm this, however, in the exceptional situation of Covid-19, use of these safer options needs to be adopted. There is sufficient rationale, pre-clinical data, and evidence of safety from longterm clinical use for common indications. This can justify the urgent need for systematic clinical research in patients with Covid-19. While intensive care should be left to super 
specialists from MM, AYUSH doctors should have access to mild to moderate cases of Covid-19 patients. AYUSH doctors should be allowed to work with allopathic doctors under a national level integrative protocol for effective management of Covid-19. The clinical use should either be as per the Monitored Emergency Use of Unregistered Interventions (MEURI) framework by the WHO (32) endorsed by the Indian guidelines (33); or should be based on strong ethical ground. MEURI evolved in the wake of the Ebola crisis when unregistered synthetic drugs were approved for treatment to tackle the epidemic. This framework was expected to be followed in all future epidemics. This principle is also applicable to traditional medicine if evidence of safety and efficacy is available. China has successfully adopted this strategy for integrating Traditional Chinese Medicine. Now is the time to apply the same principle to AYUSH drugs as immunomodulators.

Adhering to scientific standards, integrating simple and safe measures from AYUSH systems in the protocols for prophylaxis and treatment in the early stages of Covid-19 is reasonable and fair from the perspective of the larger public good. Urgent action for such integration would be justified.

Competing interests and funding: No competing interests financial or otherwise. No funding. The appointment of $\mathrm{Dr}$ Bhushan Patwardhan as Chairperson of the Interdisciplinary AYUSH Research and Development Task Force by the Ministry of AYUSH is an honorary position.

\section{References}

1. World Health Organization. Guidance for managing ethical issues in infectious disease outbreaks. Geneva:WHO; 2016

2. Nuffield Council on Bioethics. Research in global health emergencies: Ethical issues. London: Nuffield Council on Bioethics; 2020 Jan 28.

3. European Medicines Agency. Guidance on the management of clinical trials during the COVID-19 (Coronavirus) pandemic. Version 3. Brussels: EMA; 2020 Apr 28.

4. Office for Human Research Protections, Human Health Services. OHRP Guidance on COVID-19.2020 Apr 8.

5. United States Food and Drug Administration. The state of US public health bio-preparedness: Responding to biological attacks, pandemics and emerging infectious disease outbreaks. Washington: USFDA;2018 Jun [cited 2020 Apr 21]. Available from: https://www.fda. gov/news-events/congressional-testimony/state-us-public-healthbiopreparedness-responding-biological-attacks-pandemics-andemerging

6. Thompson AK, Faith K, Gibson JL, Upshur RE. Pandemic influenza preparedness: an ethical framework to guide decision-making. $B M C$ Med Ethics. 2006 Dec 4;7(1):12.

7. World Health Organization. Ethical considerations in developing a public health response to pandemic influenza. Geneva:WHO; 2007.

8. Ministry of Health and Family Welfare, Government of India. New Delhi.COVID-19 India Updates. New Delhi: MoHFW; as on 2020 Apr 21 Available from: https://www.mohfw.gov.in/

9. World Health Organisation. WHO "Solidarity" Clinical trial for COVID 19 treatments. Geneva:WHO; 2020 Mar 18 [cited 2020 Apr 21]. Available from: https://www.who.int/solidarity-clinical-trial-for-covid-19treatments

10. Indian Council of Medical Research. Recommendation for empiric use of Hydroxychloroquine for prophylaxis of SARSCov-2 infection. New Delhi: ICMR; 2020 Mar 22[cited 2020 May 10]. Available from: https://www.mohfw.gov.in/pdf/Advisoryonthe useofHydroxychloroquinasprophylasxisforSARSCoV2infection.pdf

11. National Health Commission of the People's Republic of China. Protocol on diagnosis and treatment of COVID-19 (Trial 6th edition). Beijing: NHCPRC; 2020 Mar 29[cited 2020 Apr 21]. Available from: http://en.nhc. gov.cn/2020-03/29/c_78468.htm

12. Ministry of Health and Family Welfare. National Health Policy 1993. New Delhi:MoHFW; 1993.

13. Ministry of Health and Family Welfare. National Health Policy 2002.New Delhi:MoHFW; 2002.

14. Ministry of Health and Family Welfare. National Health Policy 2017.New Delhi:MoHFW; 2017

15. Patwardhan B, Mutalik G, Tillu G. Integrative approaches for health: Biomedical research, Ayurveda and Yoga. Academic Press; 2015 Apr $7 .$.

16. Ministry of Health and Family Welfare. Government of India. Guidelines on clinical management of COVID-19. New Delhi: MoHFW; 2020 Mar 17[cited 2020 May 10]. Available from: https://www.mohfw.gov.in/pdf/ GuidelinesonClinicalManagementofCOVID1912020.pdf

17. ANI. Kerala mulls using Ayurveda to mitigate COVID-19 spread. ET Healthworld.com. 2020 Apr 19 [cited 2020 May 10]. Available from https://health.economictimes.indiatimes.com/news/diagnostics/ kerala-mulls-using-ayurveda-to-mitigate-covid-19-spread/75064043

18. Press Trust of India.Gujarat government claims drinking 'Ayurvedic Kadha' helped those in quarantine test negative for COVID-19. News 18. com. 2020 May 7 [cited 2020 May 10]. Available from https://www. news18.com/news/buzz/gujarat-govt-claims-drinking-ayurvedickadha-helped-prevent-covid-19-twitter-cant-swallow-2609823.html

19. Tillu G, Chaturvedi S, Chopra A, Patwardhan B. Public health approach of Ayurveda and Yoga for COVID-19 prophylaxis. J Altern Complement Med. 2020 Apr 20 [cited 2020 Apr 24]. Available from: https://doi. org/10.1089/acm.2020.0129

20. Kim SW, Su KP. Using psychoneuroimmunity against COVID-19. Brain Behav Immun. 2020 Mar 29. pii: S0889-1591(20)30391-3. https://doi. org/10.1016/j.bbi.2020.03.025

21. Ministry of AYUSH. Ayurveda's immunity boosting measures for self care during COVID19 crisis. New Delhi: MoAYUSH; 2020 [cited 2020 Apr 22]. Available from: https://www.mohfw.gov.in/pdf/ ImmunityBoostingAYUSHAdvisory.pdf

22. Balasubramani SP, Venkatasubramanian P, Kukkupuni SK, Patwardhan B. Plant-based Rasayana drugs from Ayurveda. Chin J Integr Med. 2011 Feb;17(2):88-94.

23. Agarwal R, Diwanay $S$, Patki $P$, et al. Studies on immunomodulatory activity of Withania somnifera (Ashwagandha) extracts in experimental immune inflammation. J.Ethnopharmacol.1999;67:27-35.

24. Ministry of Health and Family Welfare. Government of India. New Delhi. Advisory on the use of hydroxychloroquine as prophylaxis for SARS-Cov-2 infection. NewDelhi: MoHFW; 2020 Mar [cited 2020 May 10]. Available from: https://www.mohfw.gov.in/pdf/Advisoryonthe useofHydroxychloroquinasprophylasxisforSARSCoV2infection.pdf

25. Chopra A, Saluja M, Tillu G, Venugopalan A, Narsimulu G, Handa R, et al. Comparable efficacy of standardized Ayurveda formulation and hydroxychloroquine sulfate (HCQS) in the treatment of rheumatoid arthritis (RA): a randomized investigator-blind controlled study. Clin Rheumatol 2012;31:259-69.

26. Chopra A, Saluja M, Venugopalan A. Effectiveness of chloroquine and inflammatory cytokine response in patients with early persistent musculoskeletal pain and arthritis following chikungunya virus infection. Arthritis Rheumatol. 2014 Feb; 66(2):319-26.

27. Rathi S, Ish P, Kalantri A, Kalantri SP. Hydroxychloroquine prophylaxis for COVID-19 contacts in India. Lancet Infect Dis. Epub 2020 Apr 17. https:// doi.org/10.1016/S1473-3099(20)30313-3.

28. Reuters. No evidence that recovered COVID-19 patients cannot be reinfected:WHO.Indiatoday.in.2020 Apr 25 [cited 2020 May 10].Available from https://www.indiatoday.in/world/story/no-evidence-recoveredcovid-19-patients-cannot-be-reinfected-who-1671116-2020-04-25

29. Bodeker G, Kronenberg F. A public health agenda for traditional, complementary, and alternative medicine. Am J Public Health. 2002 Oct; 92(10):1582-91.

30. Daniel N.Accountability for reasonableness.BMJ.2000 Nov 5;321(7272): 1300-1.

31. Tannahill A. Beyond evidence- to ethics: a decision-making framework for health promotion, public health and health improvement. Health Promot Int. 2008 Dec: 23(4):380-90. doi: 10.1093/heapro/dan032.

32. World Health Organization. Notes for the record: Consultation on 
Monitored Emergency Use of Unregistered and Investigational Interventions for Ebola Virus Disease (EVD). Geneva: WHO; 2018 Aug 27[cited 2020 Apr21]. Available from: https://www.who.int/ebola/drc2018/notes-for-the-record-meuri-ebola.pdf
33. Indian Council of Medical Research. National Ethical Guidelines for Biomedical and Health Research Involving Human Participants 2017. New Delhi: ICMR; 2017.

\section{Twin public health emergencies: Covid-19 and domestic violence}

\section{RAKHI GHOSHAL}

\begin{abstract}
While a virus is hardly "choosy" in finding a host, the consequences of government responses to a pandemic, such as to Covid-19, have deep implications for those already-marginalised, such as women and girls. In the absence of a systematic database examining the details of the impact, this comment synthesises existing opinions, reviews and the limited available data to show how, not only the outbreak, but particularly our response to it, are increasing the incidence of domestic violence (DV) across the globe, including in India. Despite tackling a much higher Covid caseload and mortality rate than India has, countries such as France and Spain have prioritised responding to $D V$ in their respective societies, working out contingent mitigation mechanisms. Admittedly, low resource settings (LRS) such as India, have a bevy of additional infrastructure and budgetary challenges; but would that imply we do not respond to DV? This comment argues that in reality we have two public health emergencies to confront, the Covid-19 and domestic violence. It builds on the author's observations in the course of working on DV in an LRS context in India, and concludes with a set of recommendations on better responding to DV during Covid/lockdown times.
\end{abstract}

Keywords: Domestic violence, gender-based violence, Covid-19, lockdown, pandemic, low resource settings

\section{An invisible battle is launched}

Covid -19 is a major public health crisis which has enveloped millions of us. While both the rich and the poor have been affected by the virus, the consequences of this outbreak (or of any disease outbreak for that matter) are hardly as equalising. As a response to containing the infection spread, several governments have instituted home quarantine and lockdowns. Naturally, mobility is restricted and put under surveillance, and people are stuck at home. The consequences of these measures most affect the already-vulnerable the poor, women

Author: Rakhi Ghoshal (rakhi.ghoshal@gmail.com), Project Manager, CARE India, Patna, Bihar 800013 INDIA.

To cite: Ghoshal R. Twin public health emergencies: Covid-19 and domestic violence. Indian J Med Ethics. 2020 Jul-Sep; 5(3) NS: 195-9. DOI: 10.20529/ IJME.2020.056.

Published online on May 7, 2020.

(C) Indian Journal of Medical Ethics 2020 and children, the daily wage earners, the homeless. It is the first time in several decades that a pandemic has affected more than 200 countries; even though earlier outbreaks such as the Ebola and Zika also shored up deeply gendered aftermaths, systematic research on this is still at a nascent stage (1).

Seeking to partially address this gap, this comment synthesises some of the existing reviews, articles and data, especially those published from the development and humanitarian sector, to study how gender is affected in multiple ways in the Covid situation. This comment focuses particularly on how the response to Covid has triggered higher rates of domestic violence across the globe, including India. Along with the world, India too is, unfortunately, in the grip of two public health emergencies - Covid and domestic violence. This comment, in conclusion, discusses a list of plausible solutions that are applicable to low resource settings for addressing or at least mitigating - the acute challenges of aggravated domestic violence.

\section{The gendering of a disease outbreak}

Responses to public health emergencies commonly "divert resources from routine health services" $(2,3)$, and this has happened during Ebola and Zika too. In responding to Covid as well, services such as pre- and post-natal care, contraceptives, and access to sexual and reproductive health services have been seriously affected (2). The Lancet flagged this back grounding of basic medical services as a major concern and urged policy makers not to overlook non-Covid critical illnesses, especially in LRS (4). Recognising this, the Ministry of Health and Family Welfare issued a Guideline on Delivery of Essential Services (https://www.mohfw.gov.in/pdf/ EssentialservicesduringCOVID19updated0411201.pdf) where basic maternity services have been asked to be resumed. However, given the lack of transportation, their uptake will continue to face severe challenges. The effect of this will largely be borne by women and children.

Data from a cholera epidemic in Haiti in 2010 and the Ebola outbreak in West Africa in 2016 showed that such public health emergencies "place a three-fold caregiver burden on women and girls": from exposing them to greater risks of infection coupled with lower rates of treatment, to higher degrees of physical, socioeconomic and emotional distress and harm, the pandemic/epidemic collaterals are highly gendered (5). Under lockdowns such as we are in, women's basic sanitary 